olvidar el aprendizaje recibido durante su estancia en México -concretamente en Acapulco y en la Ciudad de México-.

Translating Nature: Cross-Cultural Histories of Early Modern Science llega al mundo académico como un soplo de aire fresco. Cada uno de los ensayos que reúne la colección analiza las aportaciones de los amerindios y de los europeos asentados en América a la ciencia moderna. Marroquín Arredondo y Bauer insisten en el carácter multicéntrico, transcultural y transoceánico de las ciencias naturales durante esta Era de la Traducción. Finalmente, el conocimiento y la ciencia son los protagonistas, y no las atrocidades que cometieron los españoles a partir de 1492. Todo ello se ha realizado en una edición cuidada al más mínimo detalle y con la incorporación de imágenes atractivas que embellecen el libro. Una sola pega: los editores no han incluido una bibliografía ordenada alfabéticamente, a pesar de que las obras citadas se encuentran en las notas finales.

Conxita Domènech University of Wyoming

Frederick luis Aldama, editor. Latinx Ciné in the Twenty-First Century. Tucson, AZ: University of Arizona Press, 2019. 506 pp. ISBN 13: 978-0-8165-3790-7.

Cuando un académico es tan prolífico como Frederick Aldama -hasta la fecha, ha escrito, coescrito o compilado treinta y seis libros-, es apenas lógico que, dentro de semejante abundancia, se exprese preferencia por ciertos títulos en particular. Pues bien, veintiséis años después de la publicación de The Bronze Screen: Chicana and Chicano Film Culture (1993), el fecundo texto de Rosa-Linda Fregoso, catedrática de UC Santa Cruz, este volumen representa uno de los mejores aportes de Aldama. De hecho, Fregoso cierra esta antología con una coda redactada un año antes del lanzamiento del libro. En este sentido, la labor de Aldama es encomiable, pues confiere continuidad a un quehacer fundamentado en el estudio de la representación fílmica de la comunidad latina. Quizás lo único triste sea el que, pese a representar un 18 por ciento de la población estadounidense -y un 23 por ciento de los ingresos por boletería (47)-, los latinos aún no disfrutemos de gran presencia en la producción cinematográfica de Hollywood. No es de extrañar; cual personajes de Ellison, padecemos de invisibilidad generalizada.

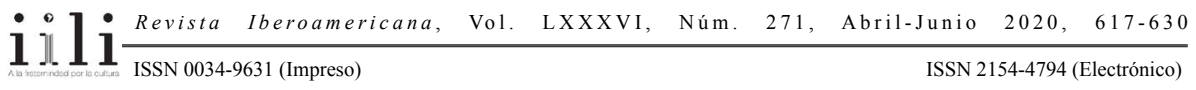


Empero, mediante esta antología, Aldama se empecina en rebatir argumentaciones en torno al bajo relieve de la cuota fílmica latina.

El libro contiene siete secciones. La primera, con artículos de índole general, incluye cuatro capítulos. El texto inicial, redactado por Debra A. Castillo, de Cornell, se centra en el documental. Castillo describe de manera extensa el panorama del documentalismo latino en el contexto de la industria nacional. En principio, aborda el asunto de la definición; es decir, ¿qué aspecto permite que un documental sea latino? Este es un asunto mucho más delicado que lo evidente a primera vista. Castillo sugiere pruebas fundamentadas en casos de la obra de Alfonso Cuarón -en los que prima el contenido-y Danny Boyle-donde el origen o la nacionalidad del autor prima por encima del contenido-. La catedrática ofrece un listado con lo más granado del documentalismo latino. Acto seguido, formula una taxonomía, categorizando ejemplos según su temática o estilo. El segundo capítulo, de Henry Puente, profesor de California State, Fullerton, es un concienzudo estudio de Pantelion Films, la empresa fruto de la colaboración entre Televisa y Lionsgate. Puente explica cómo Pantelion aprovecha el fin de semana del Día del Trabajo estadounidense, a fines de la temporada de verano, para el lanzamiento de sus cintas, a diferencia de Hollywood. Aparte de eso, la empresa cuenta con acceso a producciones de Televisa y, mediante Lionsgate, alimenta el apetito cinematográfico del público de Univisión, generando un nuevo estrellato a muy bajo costo. Puente también describe el aprovechamiento de redes sociales en campañas publicitarias altamente efectivas y un éxito relativo en términos de taquilla. No obstante, señala la falta de variedad en su oferta de películas en inglés destinadas al mercado latino, una escasa cobertura publicitaria en medios convencionales y la falta de un mayor desarrollo de farándula entre los retos de Pantelion. El tercer capítulo, de Monica Hanna, también de Fullerton, se enfoca en documentales basados en quienes cruzan la frontera. En particular, Hanna se centra en Purgatorio (2013), de Rodrigo Reyes; Kingdom of Shadows (2015), de Bernardo Ruiz; y Carne y arena (2017), de Alejandro González Iñárritu. Los tres directores son de origen mexicano, mas residenciados en EE.UU. En el caso de Iñárritu, su aporte es una instalación artística con componentes de realidad virtual. Las tres obras abordan la frontera distanciándose del narcotráfico, los desmanes de las patrullas fronterizas o los vigilantes, o un enfoque comercial, favoreciendo en su lugar el cubrimiento de personajes más comunes, como activistas, migrantes o reformistas deseosos de traer cambio a la región. El último de los capítulos de la primera sección, "Serious Docu-Games", de Rebecca Sheehan, igualmente de Fullerton, cubre los videojuegos basados en la frontera, como Borders, The Migrant Trail y Turista fronterizo. Según ella, estos juegos, al igual que el montaje de Iñárritu en Carne y arena, fomentan experiencias afianzadas en los sentidos, generando más empatía entre los jugadores y quienes cruzan la región. Para Sheehan, lo clave es la generación de un nuevo espacio, una tercera posibilidad, más allá del binarismo recurrente en el cubrimiento de la realidad fronteriza.

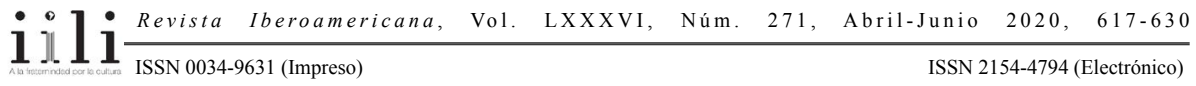


La siguiente sección contiene dos capítulos dedicados al cubrimiento de la no ficción latina. El primero, de Samuel Saldívar III, de Texas State, examina la estética de las carátulas de varios documentales como paratextos, como punto de contacto entre el público y los respectivos personajes o las correspondientes versiones de sus historias, enmarcando cada recuento dentro de un contexto específico. El segundo, de Nikolina Dobreva y Enrique García, de Middlebury, ofrece uno de los más divertidos análisis de toda la colección. De naturaleza audiovisual, explica cómo El cantante (2006), la biografía fílmica de Héctor Lavoe, representa cambios acontecidos en el género de la salsa, y en el sello Fania en particular, al lanzarse al mercado global y desatender una relación próxima con su público neoyorquino.

La tercera sección habla de las diferentes maneras en las cuales el cine latino de este siglo se encarga de plasmar la vulnerabilidad y el desasosiego de ciertas poblaciones latinas -léase, quienes se arriesgan cruzando la frontera para luego vivir sin documentación adecuada. El primer texto, de Lee Bebout y Clarissa Goldsmith, de Arizona State, emplea el thriller Desierto (2015), de Jonás Cuarón, para poner en evidencia los elementos de horror implícitos en la cinematografía latina de migración. El segundo, de Desirée J. García, de Dartmouth, ofrece una lectura de la psicología del migrante en su análisis de A Better Life (2011), la cinta de Chris Weitz - nieto de Lupita Tovar-, cuya fórmula favorece una aproximación más convencional al tema migratorio, rehuyendo los teatros de cine arte. El tercer capítulo, de Ariana Ruiz, de Iowa, examina la estética punk del cine de Jim Mendiola y explica cómo su cinta Speeder Kills (2003) brinda una dimensión espacio-temporal alterna para la ciudad de San Antonio con el consiguiente cuestionamiento del imaginario estatal anglo, tan ajeno a las poblaciones latinas. El cuarto capítulo es producto de la colaboración entre Aldama y su discípulo Carlos Gabriel Kelly. Propone un análisis exhaustivo de la obra del actor chicagüense Michael Peña mediante la figura del "palomazo", el acentuamiento de estereotipos con el fin de develar excesos identitarios. Por último, está el texto de Juan J. Alonzo, de Texas A\&M. Según él, en Machete (2010), de Robert Rodríguez, el actor Danny Trejo hace las veces de justiciero, planteando respuestas alternativas al nacionalismo de la era de Trump, fincado en el señalamiento de latinos como chivos expiatorios. Amparándose en un filme de Tarantino, Alonzo ofrece una lectura análoga del héroe chicano.

La cuarta sección lidia con la ciencia ficción. Tres de los capítulos se enfocan en Sleep Dealer (2008), la cinta de Alex Rivera. Camilla Fojas, de Virginia, explica cómo el filme y la obra de Rivera destaca el rol de los drones como herramientas del capitalismo fomentadoras de un constante ambiente de guerra; en otras palabras, en Rivera es factible reconocer cómo la tecnología violenta órdenes étnicos, raciales y de género en la frontera. El siguiente capítulo, de J.V. Miranda, de Boulder, ofrece una lectura un poco más esperanzadora de la tecnología: mediante ella, argumenta el

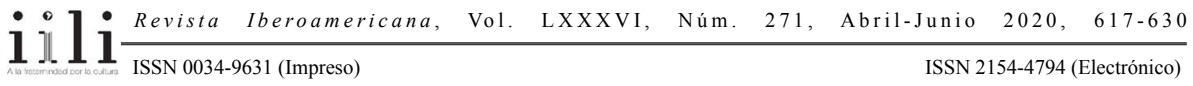


autor, se posibilita la construcción de una política de memoria cultural, la cual viabiliza una oposición a la explotación personal y la expropiación de recursos. En la siguiente entrega, Jennifer Lozano, de la Universidad de Carolina del Norte en Wilmington, emplea el rascuachismo de Rivera -el hacer más con menos, propio de alguien de escasos recursos- para profundizar lecturas simplistas de la comunidad latina propias del cine convencional. Su mejor aporte radica en destacar cómo el rascuachismo riveriano dista de cuestionar formas tradicionales de género. Como contrapunto, el capítulo final de la sección, de Matthew David Goodwin, de la Universidad de Puerto Rico en Cayey, contiene una lectura de Extra Terrestres (2017), el filme boricua de ciencia ficción, en la que explica cómo dicha cinta, lejos de postularse en oposición a la tradición hollywoodense, opta por ampararse en la panlatinidad en una suerte de gesto tangencial.

La quinta sección habla de superhéroes. Su par de capítulos, de Jorge Santos, del College of the Holy Cross, y Danielle Alexis Orozco, otra discípula de Aldama, se enfocan en Logan (2017), el episodio final de la saga de Wolverine (Carcayú), protagonizada por Hugh Jackman. Santos critica el tratamiento de la experiencia migratoria y de las vivencias de seres indocumentados; en particular, resalta el uso estratégico del silencio de Laura Kinney, la protegida del superhéroe durante la travesía de México al Canadá. Orozco se centra aún más en Kinney, detallando cómo el director James Mangold confiere mayor protagonismo al personaje para aventurar una crítica de la experiencia migratoria y del tratamiento a indocumentados en los EE.UU., mediante la cual la niña logra identificarse con su subjetividad híbrida y fronteriza.

La sexta parte analiza el mundo de la animación. Inicialmente, Sara Verónica Hinojos, de Queens College (CUNY), se encarga del audio; pasando por Speedy Gonzales y el Frito Bandito, examina el papel de las voces hasta llegar a la de Benjamín Bratt en el rol del villano mexicano El Macho en Despicable Me 2 (2010), pleno de esencialismo. Para Manuel M. Martín-Rodríguez, de UC Riverside, si bien The Book of Life (2014) y Coco (2017) ofrecen unas lecturas menos reductivas de las vivencias latinas, continúan perpetuando los estereotipos del amante latino, el bandido y de una ingenua bondad hispana. Para John D. "Río" Riofrío, del College of William and Mary, en cambio, Coco logra ir más allá del simplismo de Disney, postulando interpretaciones más complicadas de la dinámica familiar latina. Por último, Iván Eusebio Aguirre Darancou, de UC Riverside, se enfoca en Trollhunters, la serie de Guillermo del Toro para Netflix, en la que la latinidad adquiere mayor prestancia e incluso subvierte y amplía los tradicionales roles de género.

La sección final abre con un texto feminista: el análisis de Frida (2002), Selena (1997) y Dolores (2017) de Valentina Montero-Román, de Michigan. Selena es del siglo pasado, mas la autora justifica su inclusión con creces. Los filmes, argumenta Montero-Román, logran darle un sentido más extenso al quehacer feminista latino.

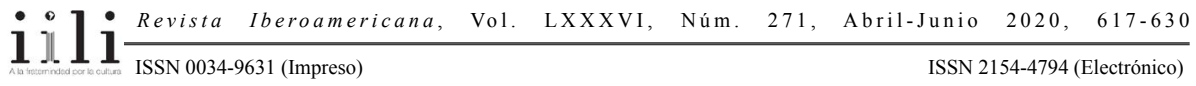


El artículo siguiente, de Richard T. Rodríguez, también de UC Riverside, analiza la latinidad y la subjetividad queer latina en el contexto del sanfranciscano distrito de Mission, diagramado por Peter Bratt en su homónima cinta de 2009. Para Rodríguez, lo vital del filme es su denuncia de la homofobia latina. La sección cierra con el texto de Mauricio Espinoza, de la Universidad de Cincinnati, dedicado al cubrimiento de la latinidad en los deportes con Girlfight (2000) y McFarland, USA (2015). En la primera, se da el caso de una latina empoderada; en la segunda, se critica cómo, para destacar, los latinos aún tienen que ceñirse al orden de una ideología preceptiva.

Dadas las magnas y ambiciosas intenciones de la colección, no resta sino admirar el entusiasmo de Aldama en su papel de campeón de los intereses latinos. Es tal su fervor que, en la introducción (11), termina cambiándole el apellido a Dominic Toretto (pese a nombrar correctamente a su hermana varias líneas más abajo), el personaje de la saga de The Fast and the Furious (2001) actuado por Vin Diesel, latinizándolo -le convierte en Dominic Torres-. Pronto llegará el 2044. Para ese entonces, ninguna etnicidad podrá jactarse de una mayoría demográfica. El cine es materia de representación -de verse en la pantalla grande, según decía Monsiváis-- Habrá que ver si el gracioso desliz de Aldama, evidencia de su apoyo irrestricto a una creciente cuota cultural latina, presagia una paulatina aceptación y renovada visibilidad en años venideros.

Héctor Danilo Fernández L’Hoeste Georgia State University

\section{Hannah Burdette. Revealing Rebellion in Abiayala. The Insurgent Poetics of} Contemporary Indigenous Literature. Tucson: The University of Arizona Press, 2019. ISBN 978-0-8165-3865-2.

La Dra. Hannah Burdette a través de este libro nos ofrece un panorama amplio de las literaturas originarias de Abiayala, además nos muestra las conexiones y diálogos que se han establecido desde los pasados, presentes y visiones del futuro. El libro tiene la meta de "ilustrar las formas en la literatura indígena contemporánea ofrece una alternativa viable a las formas hegemónicas de conocimiento conectadas al neoliberalismo, el capitalismo y los valores eurocéntricos de progreso e individualismo" (mi traducción, Introducción, 6). Y es a través de la estructura del libro donde muestra

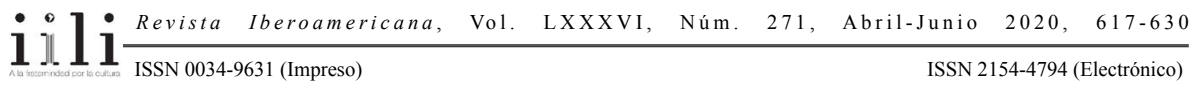

